\title{
Circuit
}

Musiques contemporaines

\section{Cirque nominatif}

\section{Michel F. Côté}

Volume 6, numéro 2, 1995

Musique actuelle?

URI : https://id.erudit.org/iderudit/902133ar

DOI : https://doi.org/10.7202/902133ar

Aller au sommaire du numéro

\section{Éditeur(s)}

Les Presses de l'Université de Montréal

ISSN

1183-1693 (imprimé)

1488-9692 (numérique)

Découvrir la revue

Citer cet article

Côté, M. F. (1995). Cirque nominatif. Circuit, 6(2), 27-30.

https://doi.org/10.7202/902133ar

Ce document est protégé par la loi sur le droit d'auteur. L'utilisation des services d'Érudit (y compris la reproduction) est assujettie à sa politique d'utilisation que vous pouvez consulter en ligne.

https://apropos.erudit.org/fr/usagers/politique-dutilisation/
Cet article est diffusé et préservé par Érudit.

Érudit est un consortium interuniversitaire sans but lucratif composé de l'Université de Montréal, l'Université Laval et l'Université du Québec à Montréal. Il a pour mission la promotion et la valorisation de la recherche. https://www.erudit.org/fr/ 


\title{
Cirque nominatif
}

\author{
Michel F. Côté
}

Nous y voici donc encore une fois : qu'est-ce que la « musique actuelle »?

Je ne mets pas en doute la pertinence de bien nommer les choses ef les gestes, mais j'avoue qu'aujourd'hui la question et son débat me plongent dans un état de grande lassitude. C'est qu'il y a là un vide de sens à faire fuir le plus tenace compositeur soucieux de bien définir et situer son esthétique. Penser/classer est pourtant une logique de réflexion intrinsèque au processus de composition, et le créateur doit donc pouvoir identifier puis affirmer son appartenance esthétique et sa filiation. II n'y a pas d'autre moyen de susciter le respect réciproque. Mais voilà, cette attitude élégante de réciprocité est beaucoup trop rare dans notre univers musical parfois suffocant; petit milieu provincial dans lequel tous et toutes semblent supporter tant bien que mal la même appellation: "musique actuelle», comme dentisterie actuelle ou crêpage actuel. Cela vous plaît, vous?

Dans le Globe and Mail du 4 mai 1989, le journaliste Mark Miller écrivait : "The latest LP from Montreal's east end, like all the rest, must come with the qualification that it's not, ah, exactly, um, jazz. Not exactly anything in particular, actually. Musique actuelle, they call it at the corner of St-Denis and Mont-Royal'"). „A l'époque, je croyais fermement que l'appellation « musique actuelle $»$ identifiait spécifiquement cette musique qui se caractérise par une croisée des chemins sans précédent, ce métissage musical incontournable et vital que l'on retrouve depuis 1982 en partie illustré par les productions inscrites au catalogue du label Ambiances Magnétiques. Avec cette audace propre à l'invention, sans aucun interdit, nous avions alors choisi de vastes champs d'investigation esthétique : pas de système; pas de lois; aucun intermédiaire, nous devenions nos propres interprètes, nous avions pris le parti du franc-parler et de la hardiesse musicale. Si style il y a, il s'exprimait sans souci de pureté. Ne demeure que le plaisir (le devoir, aurait écrit un sot) de cueillir, trier et compos(t)er sans cesse nous-mêmes les fruits de ces vastes champs. Malgré le nombre restreint $d^{\prime}$ adhérents à cette nouvelle scène dite de « musique actuelle », le mouvement était déjà bien amorcé : Michel Levasseur et son
(1) « Le dernier microsillon de l'Est de Montréal, comme tout le reste, doit être pris avec cette remarque que, ah! hum ! ce n'est pas exactement du jazz. Pas exactement quoi que ce soit de particulier, en fait \& musique actuelle *, on appelle ça comme ça au coin de Saint-Denis et MontRoyal. » [Traduction libre.] Extrait d'un commentaire critique que le journaliste Mark Miller formulait à propos d'une nouveauté alors parue sur étiquette Ambiances Magnétiques. 
festival international $(F \mid M A V)^{(2)}$ était aussi au rendez-vous, au centre de cette esthétique qui prenait le risque admirable de n'être rien en particulier ${ }^{(3)}$.

En 1990, avec le festival Montréal Musiques Actuelles et son succès à la fois populaire et médiatique, le terme devenait soudainement très attrayant. Pendant neuf mois, la « musique actuelle made in Quebec » a eu le vent dans les voiles, et de nombreux compositeurs et mélomanes de divers horizons furent séduits par le troublant « sex appeal » de cette nouvelle désignation. Il y a même eu quelques remarquables journalistes pour affirmer qu'avec ce nouveau nom simple et fabuleux, la «musique de demain avait de l'avenir ». Effectivement, le nom a eu du succès. Trop: quatre années plus tard, cet avorton dénominatif a perdu toute signification précise, si ce n'est qu'une vague et large référence au monde luxuriant de la création musicale actuelle, tous genres confondus. De ce qui semblait être un terme désignant une musique hors-la-loi, on passait maintenant à une appellation générale d'une nullité consommée. Bref, plus aucune référence stylistique, même approximative, plus de qualificatif d'école, tout le monde fait de la musique actuelle : il y a la tienne, la mienne, celle des autres, jeunes ou vieux, tous pour un, il n'y a plus qu'une immense confrérie! Bravo.

Cette illusion nominative ne fut pas sans conséquences. D'une simplification ridicule dans laquelle un quatuor à cordes bien ficelé devient soudainement le "frère de sang "d'une improvisation pour guitare électrique, nous passions progressivement à un sérieux état de handicap collectif : il y a ici une fausse représentativité, une consanguinité totalement fallacieuse. Une situation que notre "petit milieu " n'a vraiment pas les moyens de s'offrir et qui ne fait que grossir un problème urgent : la nécessité d'une juste et pluraliste représentativité médiatique (entre autres problèmes d'actualité).

Allons-y donc clairement : Bruce Mather et Martin Tétreault font-ils tous les deux de la «musique actuelle»? Et pourquoi le Conseil des arts du Canada fait-il une différence entre ces deux domaines musicaux qu'il appelle respectivement la « composition classique contemporaine " et la " musique actuelle »? Et qu'en est-il de la représentativité de l'électroacoustique ? Gilles Gobeil et Michel Ratté sont-ils de la même esthétique ? L'électroacoustique et l'improvisation partagent-ils le même espace musical ? Oui ou non ? De toute évidence, non. "Musiques actuelles " au pluriel comme terme générique englobant, peut-être, mais l'utilisation « musique actuelle " au singulier comme dénominateur commun impose un règne du flou esthétique inacceptable. C'est peutêtre commode, mais c'est également idiot. Comme l'écrit pertinemment Jean Dubuffet : «l'invention poétique implique que les concepts soient extensibles, prêts à déborder l'un sur l'autre », mais pour cela, il faut d'abord être capable de distinguer et nommer intelligiblement les univers que l'on veut faire « déborder l'un sur l'autre ».
(2) Le Festival international de musique actuelle de Victoriaville, dont la première édition a eu lieu en 1983.

(3) Un autre article que celui-ci serait nécessaire pour bien définir cet univers musical dont les membres d'Ambiances $\mathrm{Ma}$ gnétiques sont parmi les principaux représentants. Sachez tout de même qu'il prend racine au cours des années 1960, période de vive agitation où différents styles musicaux jusqu'alors relativement imperméables se bousculent les uns les autres (trois principaux trouble-fête : le jazz, le rock et les musiques expérimentales américaines). 
Par souci éthique et historique, en tant que membre de Ambiances Magnétiques, i'aurais tendance à revendiquer encore ce terme descriptif de «musique actuelle », ce que Mark Miller appelait la musique de «l'Est de Montréal (...) au coin de Saint-Denis et Mont-Royal ». Paradoxalement, je ne ressens plus d'urgence à penser/classer autre chose que des sons; toute velléité nominative $m^{\prime}$ a abandonné, conséquence d'un ras-le-bol temporaire. Pour l'instant, je laisse à d'autres le soin récréatif de nommer. Et puis, très honnêtement, en musique je préfère li)ouir les sons plutôt que penser les mots ; comme dans le champ chaud de la sexualité je préfère palper la peau plutôt que de voir la vidéo. Il y a comme un vice de forme dans tout ce cirque nominatif : en musique, le sex appeal ne se situe pas du côté des mots, il se situe du côté de l'écoute ardente. 


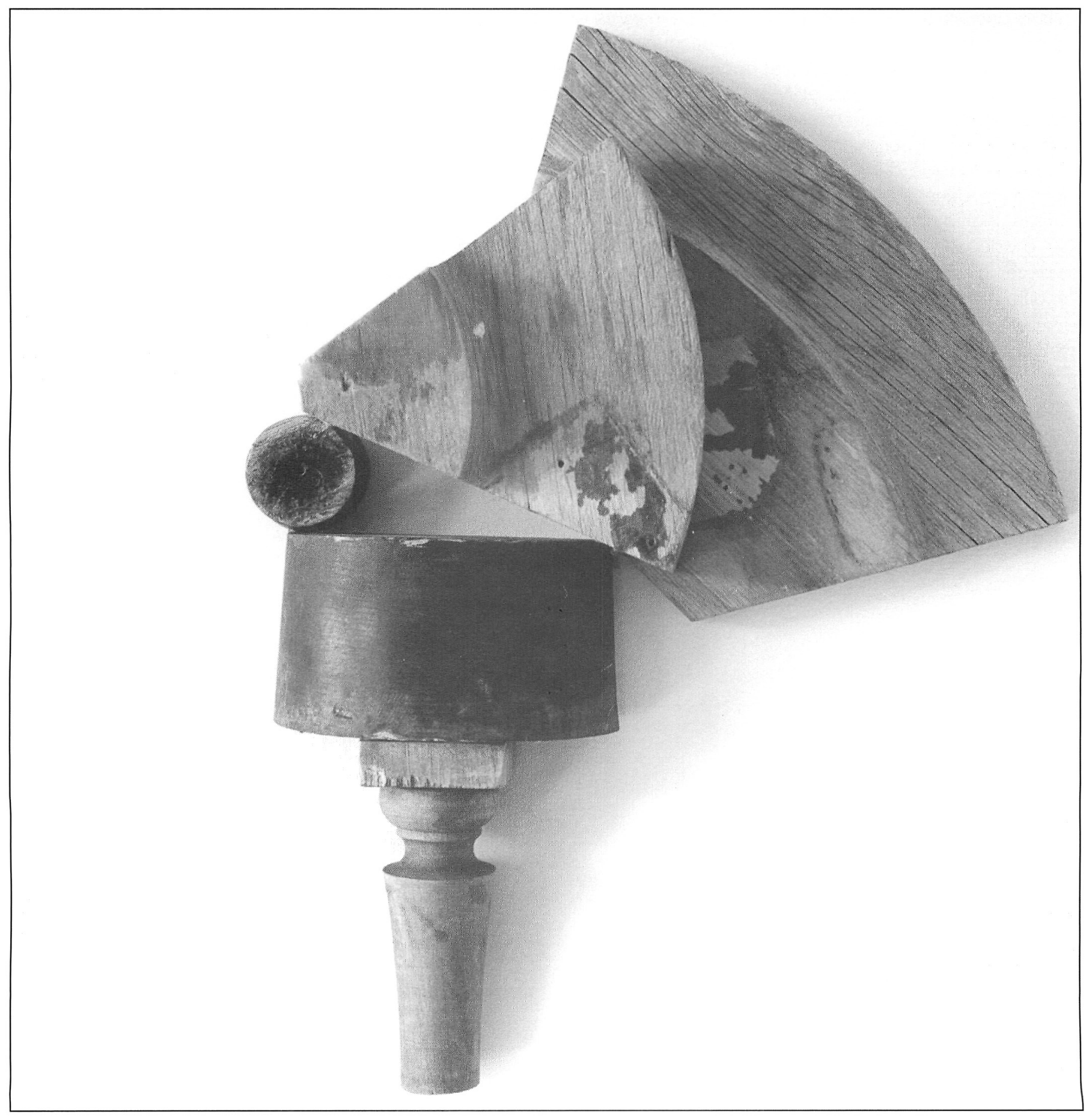

